THE WABASH CENTER

JOURNAL on TEACHING

\title{
Multidimensional Curriculum Enhancing Future Thinking Literacy: Teaching Learners to Take Control of Their Future
}

\author{
Hava E. Vidergor \\ Leiden, The Netherlands: Brill Sense, 2018 (vii + 317 pages, ISBN 978-90-04-37518-5, \\ \$119.00)
}

\section{Reviewed By}

Alicia Brienza

Stonehill College
Hava E. Vidergor proposes the Multidimensional Curriculum Model (MdCM) as an essential framework for all educators in diverse disciplines from Common Core subjects to the development of interpersonal skills like global citizenship and leadership. Vidergor's work is positioned within a global context and, while the Israeli education system is the prime example, all educators gain valuable unit plans and individualized lessons that are focused, creative, and engaging for all learners. Specifically, Vidergor's inclusion of modifications for gifted/able students, English language learners, and students with disabilities highlights MdCM's adaptability. By the conclusion, readers find that $\mathrm{MdCM}$ is both exciting and fun for educators considering the future of education.

Vidergor illustrates future thinking literacy as a dynamic and innovative approach to essential skills-building, drawing from the Israeli Ministry of Education's definition of "meaningful learning" as "a process that results in a significant and lasting change in individuals' behavior and function" (1). MdCM combines critical thinking, collaboration, creativity, cross-cultural understanding, computing, and communication, and Vidergor sets her work apart by intentionally laying out each of these components in the subsequent chapters. Indeed, Vidergor's rich interweaving of the liberal arts in a lesson on genetics and integration of consumerism with percentages will excite educators who feel that crossover between disciplines is lacking or that resources are not sufficiently clear. Vidergor's intuitive layout is a platform for educators who want to utilize cross-disciplinary topics creatively but are unsure where to start.

Most importantly, Vidergor's lesson plans are consistent and intentional, and readers become immersed in the practice of asking students to envision themselves in a larger, global context. Vidergor explains that teaching future thinking literacy is comprised of four strategies: (1) Predictions, (2) Scenarios, (3) Global perspective, and (4) Wild Cards, whereby students have full creative license to imagine illogical circumstances and concoct far-reaching solutions (11). These four strategies spur innovation while building executive function skills; in turn, students are engaged and feel connected to their learning as creative agents with a broader conceptual awareness of course content. With terms like creative output and the use of diverse media, Vidergor's future thinking literacy is reflected in a more modern vocabulary and format. Particularly illuminating is the sense that students today are more interconnected, global, and aware of diverse perspectives due to advancing technology. In order to be effective, educators are tasked with keeping pace and positioning the current generation's context at the forefront. While challenging to continuously adapt, Vidergor's work is a blueprint for educators to finally approach the larger, future-oriented issues that matter most to students like climate change, global inequality, international women's rights, and energy conservation. Finally, educators will feel that fundamental questions about our society's future are imminently necessary.

For Catholic educators, Vidergor's work is precisely the foundation we need to further emphasize the Global Church with a forward-thinking, progress-oriented attention to our curriculum. Vidergor's connection across disciplines inspires Catholic educators to integrate Church teachings, mission, history, comparative religious studies, and practices as seamlessly whether in a theology or calculus course. As a higher education administrator in a Catholic institution, I incorporated MdCM and future thinking literacy in a training for tutors connecting Jean Jacques Rousseau's Emile: On Education and the reciprocal relationship between tutors and students. Inspired by Vidergor, the tutors scripted and roleplayed a tutoring session in the year 2060. The naturalness, creativity, and depth in their responses affirmed that Vidergor's work is a timely response to students who are already thinking about their presence in the future.

312 2021; 2:1 312-312 The Wabash Center Journal on Teaching

This work is licensed under a Creative Commons Attribution-NonCommercial 4.0 International License 